\title{
COX-2 gene expression and methylation profile in Sapajus apella as an experimental model for gastric adenocarcinoma
}

\author{
Danilo do Rosário Pinheiro ${ }^{1}$, Maria Lucia Harada ${ }^{1}$, Rommel Mario Rodriguez Burbano ${ }^{2}$ and Barbara do \\ Nascimento Borges ${ }^{1}$ \\ ${ }^{1}$ Molecular Biology Laboratory, Instituto de Ciências Biológicas. Universidade Federal do Pará, Belém, PA, \\ Brazil. \\ ${ }^{2}$ Human Cytogenetics Laboratory, Instituto de Ciências Biológicas. Universidade Federal do Pará, Belém, \\ PA, Brazil.
}

\begin{abstract}
Gastric cancer (GC) remains one of the main causes of cancer-related death worldwide. There are two distinct histological types of GC: diffuse and intestinal. The latter is characterized by the presence of pre-neoplastic lesions. One of the most frequently altered enzymes in intestinal GC is COX-2, an important lesion marker. This work aimed to study COX-2 methylation and expression in N-methyl-N-Nitrosurea (MNU)-induced intestinal GC in six Sapajus apella animals. The partial promoter sequence of $S$. apella COX-2 gene was obtained and used to identify transcription factors and cis-regulatory element binding sites. The COX-2 methylation pattern was assessed using Methylation-Specific PCR (MSP), and expression was analyzed by immunohistochemistry (IHQ). A total of 20 samples were obtained. A 675 bp fragment of the S. apella COX-2 promoter region was obtained, and it was $99.2 \%$ and $68.2 \%$ similar to $H$. sapiens and $S$. boliviensis, respectively. Similar to humans, several transcription factors and cis-regulatory element binding sites were identified in the $S$. apella sequence. MSP revealed that all samples were methylated. However, IHQ results demonstrated positive COX-2 expression in all pre-neoplastic and tumoral samples. The results suggest that the analyzed fragment is not crucial in COX-2 regulation of GC in S. apella.
\end{abstract}

Keywords: PTGS2, gene regulation, animal model, gastric cancer.

Received: December 5, 2016; Accepted: October 19, 2017.

Gastric cancer (GC) is the fourth most diagnosed cancer and the second highest mortality rate among all types of cancers worldwide. Its incidence is influenced by several factors, including Helicobacter pylori (H. pylori) infection, smoking, dietary habits, and host genetic susceptibility (Yan et al., 2013).

Among the many genes involved in gastric carcinogenesis $C O X-2$ may play an important role. Cyclooxygenase-2 (COX-2) is an inducible enzyme that catalyzes the conversion of arachidonic acid to prostaglandins in response to several inflammatory stimuli. The progression from initial gastric lesions to gastric cancer has been correlated with COX-2 over-expression, suggesting that its activity may be involved in gastric carcinogenesis onset ( $\mathrm{Li}$ et al., 2012).

It is known that non-human primates are considered a useful model for carcinogenic studies due to their close

Send correspondence to Bárbara do Nascimento Borges. Laboratório de Biologia Molecular "Francisco Mauro Salzano", Instituto de Ciências Biológicas, Universidade Federal do Pará, Cidade Universitária Prof. José da Silveira Netto, Rua Augusto Correa 01, 66075-970 Belém, PA, Brazil. E-mail: bnborges@ufpa.br phylogenic relationship to humans resulting in a great similarity regarding anatomy, physiology, biochemistry, organ systems, and long life span as compared to rodents (Takayama et al., 2008; Costa et al., 2011). Thus, the aim of this study was to evaluate the $C O X-2$ gene methylation profile and expression in gastric mucosa samples at different pathogenic stages of intestinal gastric cancer in an experimental model developed in primates of the Sapajus apella species.

Six adult Sapajus apella primates identified with microchips and individually housed in Centro Nacional de Primatas (CENP), Pará State, Brazil, were treated with oral fresh doses of N-Methyl-N-nitrosourea (MNU) (N1517 Sigma-Aldrich, USA) at a dosage of $16 \mathrm{mg} / \mathrm{kg}$ body weight, and also received drink water containing MNU in light-shielded bottles daily. As previously described, this concentration was responsible for chemically-induce gastric carcinogenesis (Costa et al., 2011). The animals were fed with fresh fruit, vegetables and commercial food pellets (FOXY Junior Supreme 28\% crude protein; PROVIMI, Brazil) and inspected daily and their clinical symptoms were recorded. All the procedures were conducted by veter- 
inarians from CENP. The details of animal welfare and steps taken to ameliorate suffering were in accordance with the recommendations of the Weatherall report, "The use of non-human primates in research'. This study was approved by the Ethics Committee of Universidade Federal do Pará (PARECER MED002-13).

All animals were considered healthy at the time of first blood sampling, endoscopy, and ultrasound. This was confirmed by the animals' behavior as judged by the veterinary check. Periodic endoscopic tests with gastric biopsy and ultrasound (days 0, 90, 120, 300 and 940) were performed throughout the treatment for monitoring. Biopsy samples were subjected to histopathological analysis and sent to the Laboratório de Biologia Molecular at Universidade Federal do Pará (UFPA) for molecular analysis. During the experiment, five animals that developed preneoplastic lesions died from intoxication, showing typical symptoms such as confusion, sleepiness, tremor, hyperthermia, diarrhea, vomiting, urinary retention, cutaneous eruptions, and ulcerative oral lesions. They also presented renal, hepatic and respiratory failure and steatosis. Animals suffering and with presumed terminal illness due to adverse side effects were euthanized by intravenous administration of Ketaral (Cetamine chloride, $50 \mathrm{mg} / \mathrm{kg}$ ), Dormonid (Midazolam, $50 \mathrm{mg} / \mathrm{kg}$ ) and Methotrimeprazine (Levomepromazine, $50 \mathrm{mg} / \mathrm{kg}$ ). The surviving animal received Canova treatment and was submitted to a surgical removal of the tumor, being clinically monitored for one year after the end of the experiment. During this period it did not show any complications resulting from the treatments (Costa et al., 2011).

DNA was obtained using the QIAamp DNA Mini Kit (Qiagen) according to the manufacturer's instructions and quantified using a NanoDrop 1000 Spectrophotometer v3.7 (Thermo Scientific).

The genomic sequence for the $S$. apella $C O X-2$ promoter region was obtained from primers designed using conserved regions of the $C O X-2$ sequence from Homo sapiens (GenBank access code: NG_028206) and Saimiri boliviensis (GenBank access code: AGCE_01110177). The $\mathrm{COX}$-2 primer sequences were as follows: sense 5'-GATCACTTCAAAATGAATTCAGGAT-3' and antisense 5'-GCTACGAAGATAGATTACAGTTATG-3'.

Polymerase chain reaction (PCR) was performed on the normal gastric mucosa samples. The reaction had a final volume of $25 \mu \mathrm{L}$ containin: $50 \mathrm{ng}$ of template DNA, $10 \mathrm{pM}$ of each primer, $0.20 \mathrm{mM}$ of each dNTP, $2.5 \mathrm{mM} \mathrm{MgCl}_{2}$ and 0.5 U Taq DNA polymerase (Invitrogen). After PCR, the DNA fragments were sequenced using an ABI 3130 automated sequencer (Life Technologies). The sequencing reaction was performed using the BigDye Terminator v3.1 Cycle Sequencing Kit (Life Technologies).

The obtained sequence was aligned using the BioEdit program (Hall, 2011) with the same sequences used for primer design. Analysis of the promoter region was con- ducted by comparing the obtained sequence for $S$. apella with the human sequence using the Transcriptional Factor search program (TFsearch) (Heinemeyer et al., 1988) to identify putative transcription factor and $c i s$-regulatory element binding sites.

To analyze the methylation pattern of the of $S$. apella $C O X-2$ promoter, $\mathrm{CpG}$ islands were identified in the promoter fragment using MethylPrimer Express software (Life Technologies). Computational analyses revealed the presence of a 127-bp CpG island containing seven CpG sites located between positions 388 and 514 of the sequenced fragment.

Analysis of the $C O X-2$ promoter methylation pattern was performed by MSP using selected primers by the MethPrimer software (Li and Dahiya, 2002): COX2MSPMF 5, AAATAATTAATATAAACTCCG CGAA 3' and COX2MSPMR 5' TAGGGAGAGAAATG TTTTAAGGTATAC for the methylated fragment; COX2MSPUF 5' AAATAATTAATATAAACTCCACA AA 3' and COX2MSPUR 5' TAGGGAGAGAAATGTT TTAAGGTATATGT 3' for the unmethylated fragment. The MSP approach combines the treatment of genomic DNA with sodium bisulfite with PCR amplification using specific primers containing at least one $\mathrm{CpG}$ site (Herman et al., 1996). PCR was performed using the Hot Start strategy starting with a cycle of $95^{\circ} \mathrm{C}$ for $5 \mathrm{~min}$. After this stage, 40 cycles of $95^{\circ} \mathrm{C}$ for $30 \mathrm{~s}, 51^{\circ} \mathrm{C}$ for $30 \mathrm{~s}$ and $72^{\circ} \mathrm{C}$ for $30 \mathrm{~s}$ were repeated, followed by a final extension at $72{ }^{\circ} \mathrm{C}$ for 5 min. The PCR product (136 base pairs for both fragments) was loaded onto a 3\% agarose gel and visualized using GelRed (Biotium Inc.) staining under UV light.

To detect COX-2 expression in tumor cells the streptavidin-biotin-peroxidase-based immunohistochemical method was performed as described previously (Hsu et al., 1981) with modifications. First, tumor tissue sections (4 $\mathrm{mm}$ thickness) were deparaffinized in xylene and rehydrated in a graded series of ethanol. The epitope retrieval was heat-induced followed by incubation with diluted (1:60) COX-2 primary human monoclonal antibody (Zymed/Thermo Fisher, COX2 Monoclonal Antibody COX 229, Catalog Number 35-8200). Histological sections were covered and the slides were incubated at $4-8{ }^{\circ} \mathrm{C}$ for 16 h. A universal peroxidase-conjugated secondary antibody kit was used for the detection system (LSAB + system, DakoCytomation) following the manufacturer's recommendations. The DAB + System (3,3-diaminobenzidine) (DakoCytomation) was used as the chromogen, following the manufacturer's recommendations, and haematoxylin was used as the counterstain. Any nuclear stain was considered as a positive result, irrespective of intensity and cytoplasmic staining. Samples were considered positive when $10 \%$ or more neoplastic cells were positive for COX-2.

A total of 20 samples was analyzed in this work: six from normal mucosa, six from gastritis, five from atrophic gastritis, two derived from intestinal metaplasia, and one 
sample of intestinal type of gastric cancer derived from the only $S$. apella that developed the tumor.

When we used the normal mucosa samples, we obtained a 675 bp identical fragment (GenBank accession number KR011346) of the $S$. apella $C O X-2$ promoter by PCR. It was $99.2 \%$ similar to the $H$. sapiens fragment (4 transitions and 1 transversion) and $68.2 \%$ similar to the $S$. boliviensis promoter sequence (134 gaps, 44 transitions and 37 transversions).

We then analyzed the promoter fragment to identify potential transcription factor and cis-regulatory element binding sites. We identified several transcription factor binding sites, primarily CdxA, GATA-1 and GATA-2, and cis-regulatory elements, including p53 Responsive Elements (P53RE), NF-Y and STAT (Figure 1). Of all the sites examined, only one in the final portion of the fragment was distinct in humans and $S$. apella (CDXA in humans; GATA-1 and GATA-2 in S. apella).

When examining the methylation pattern of the $C O X-2$ promoter, all samples were methylated, regardless of disease state (normal tissue, pre-neoplastic lesions and tumor tissue) (Figure 2).

Immunohistochemistry was performed to examine COX-2 protein expression in the samples. The results showed that normal samples did not express COX-2, while samples with pre-neoplastic lesions (chronic gastritis, atrophic gastritis and metaplasia) or tumors were positive for COX-2 expression (Figures 3 and 4).

Animal models are a valuable tool to study the origin and molecular mechanisms of cancer and can be used to develop and test new therapeutic strategies, including gastric cancer (Tsukamoto et al., 2007).

Compared to rodents, nonhuman primates are more similar to humans in relation to their genetic evolution, anatomy, physiology, biochemistry and organ system (Puente et al., 2006). In this work, we used the S. apella species, an excellent model for biological research purposes, including dental and medical (Gaetti-Jardim Jr et al., 2012), as it can be easily accommodated in Primate Research Centers due to its flexibility, small size, adaptability,

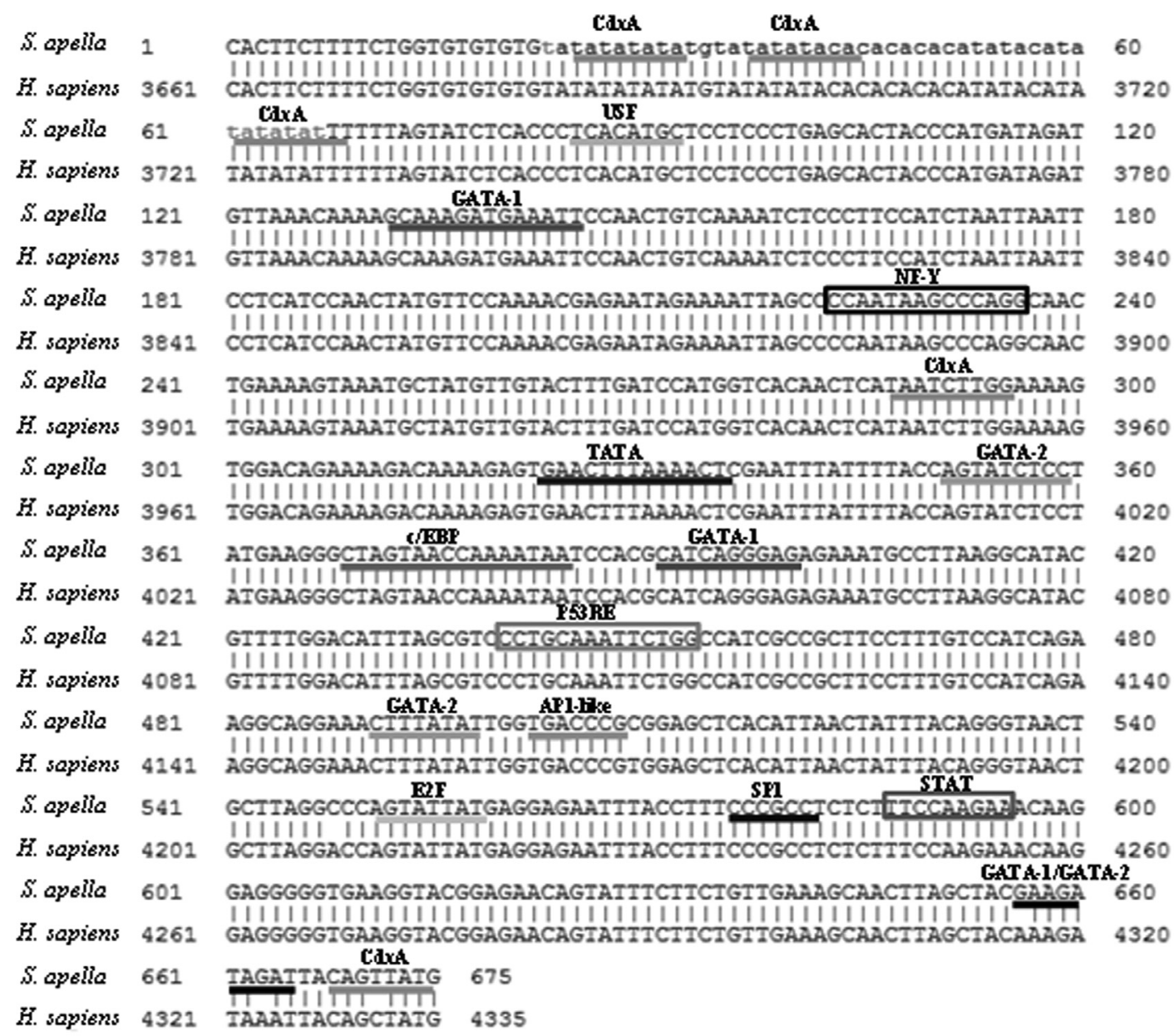

Figure 1 - Binding sites in the $S$. apella sequence. Binding sites for regulatory cis-elements (highlighted in boxes) and transcription factors (underlined) in the $S$. apella partial promoter sequence. 


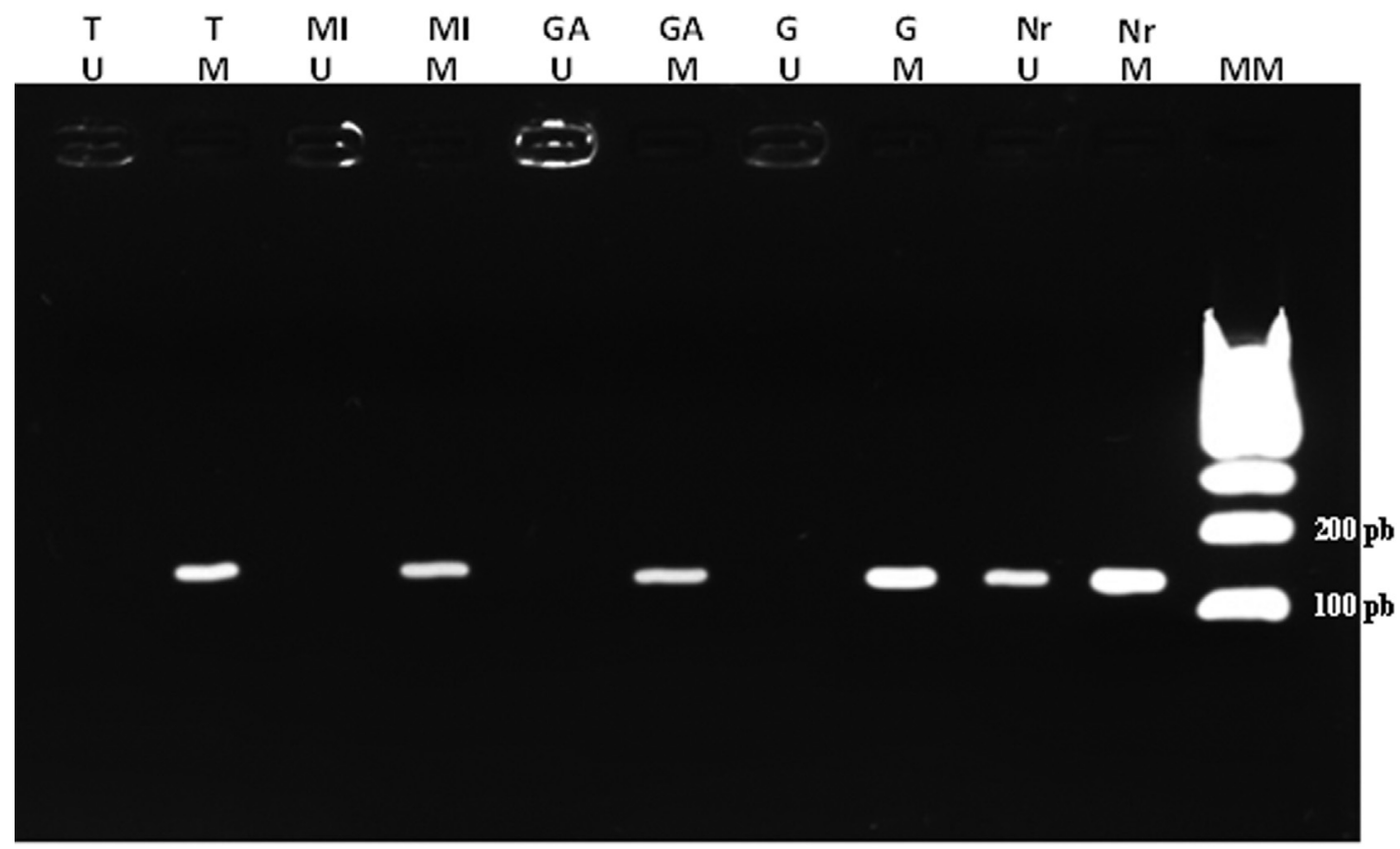

Figure 2 - MSP results. Agarose gel (3\%) with MSP results. MM: Molecular Marker. M: methylated. U: unmethylated. Nr: Normal tissue. G: Gastritis. GA: Atrophic gastritis (atrophy). MI: Intestinal metaplasia. T: tumor.

opportunism, and because their body size allows for the performance of routine diagnostic tests such as endoscopy, blood sampling and biopsy in the same animal. Besides, our group was the first to establish a gastric carcinogenic model in $S$. apella (Costa et al., 2011).

According to the classification proposed by Lauren (1965), gastric cancer can be divided into two main forms, the intestinal and diffuse types. The MNU-induced lesions in this experiment are consistent with the typical intestinal pre-neoplastic stages. Six animals developed gastritis, and of these, five developed dysplasia, and only two developed metaplasia. Only one monkey survived treatment and developed a tumor. The lesions that appeared during tumor

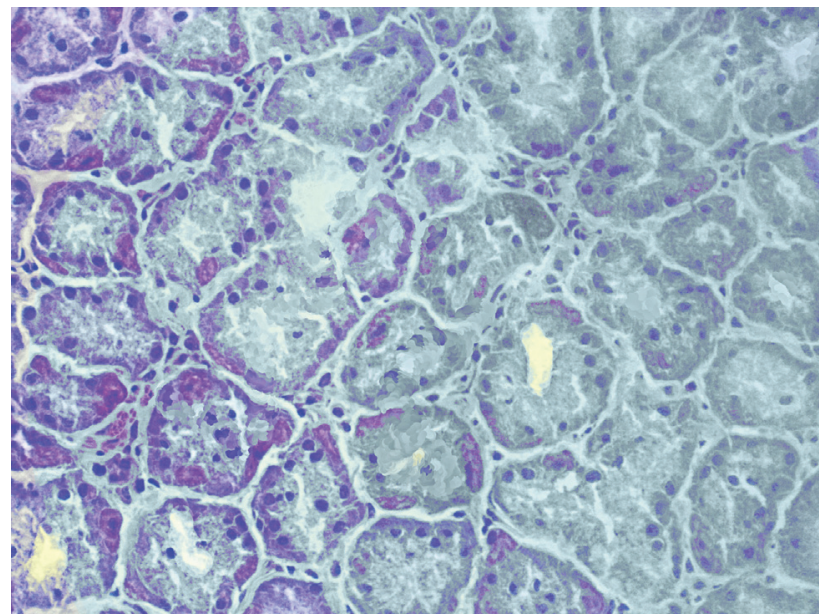

Figure 3 - Non-neoplastic gastric mucosa negative for COX-2 immunoreactivity. development were similar to those that occur in humans as a multistep process (Lauren, 1965).

Several lines of evidence indicate that inflammatory responses play important roles in cancer development and progression (Kinoshita et al., 2013; Oshima and Oshima, 2013). One of the inflammatory networks involved in gastric carcinogenesis is the cyclooxygenase-2 (COX-2)/prostaglandin E2 (PGE2) pathway. COX-2 is an inducible rate-limiting enzyme for prostaglandin biosynthesis that has an essential role in inflammatory responses (Oshima and Oshima, 2013). Induction of COX-2 expression is found in more than $90 \%$ of gastric cancers and is especially

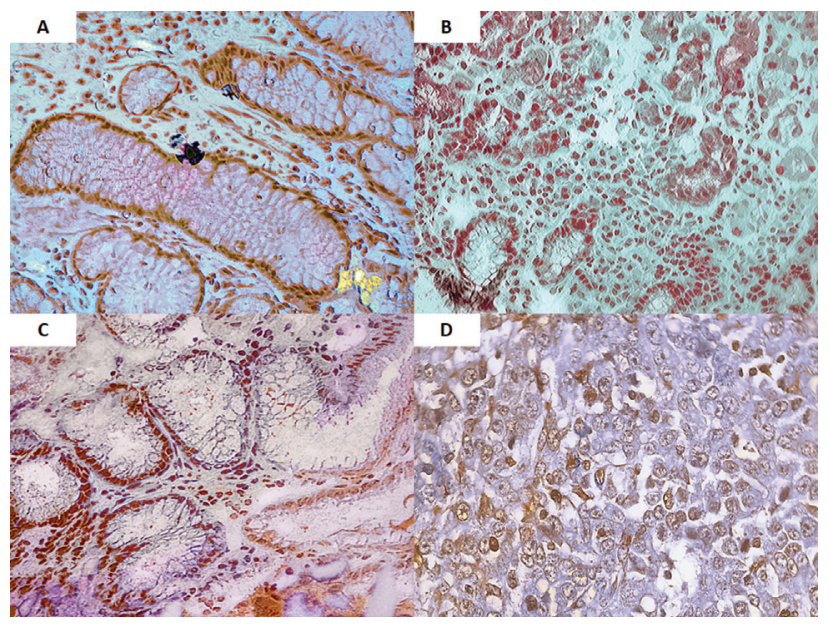

Figure 4 - Pre-neoplastic and neoplastic lesions positive for COX-2 immunoreactivity. (A) Chronic gastritis with plasmocytes; (B) Atrophic gastritis (atrophy); (C) Intestinal metaplasia; (D) Tumor 
triggered by H. pylori infection (Echizen et al., 2016). This inflammatory microenvironment promotes the activation of several pathways such as PI3K/Akt/GSK-3 $\beta$ and Notch, which activate the COX-2/PGE2 pathway, leading to gastric tumorigenesis (Thiel et al., 2011; Rivas-Ortiz et al., 2017). In such a way, COX-2 expression is increased in premalignant and malignant lesions, suggesting that this protein plays a role in early gastric carcinogenesis and in tumor progression (Thiel et al., 2011; Cheng and Fan, 2013). Besides being stimulated by an inflammatory process, it is also known that COX-2 expression also plays a role in chemically-induced gastric cancer, using MNU, in rodents (Thiel et al., 2011) and non-human primates (Costa et al., 2011).

COX-2 expression is also regulated by several cis elements in its promoter region, such as binding sites for $\mathrm{NF}-\kappa \mathrm{B}$, and by DNA promoter methylation, as suggested by several studies (Wang et al., 2005; de Maat et al., 2007; Alves et al., 2011), and its expression was associated with several clinicopathological features of gastric carcinogenesis, such as intestinal histological subtype, proximal location, tumor size and advanced clinical stage (Cheng and Fan, 2013).

As the S. apella COX-2 promoter sequence was not available in the literature, we designed primers from conserved sequences of $H$. sapiens and $S$. boliviensis, a species phylogenetically close to $S$. apella. Upon analysis of the obtained promoter fragment, we observed great similarity between the $S$. apella monkey and the human sequence (99.2\%), confirming that it was a conserved portion of the promoter region.

In humans, the $C O X-2$ promoter region is approximately $1,700 \mathrm{bp}$ long and contains several binding sites for cis-regulatory elements and transcription factor binding sites (Wang et al., 2007). In the human promoter, many sites have been identified, including those for $\mathrm{C} / \mathrm{EBP} \beta$, NFк $\beta$, NF-Y, PEA3, E-box, SP-1, and AP-1, and different combinations of transcription factor binding are responsible for modulating gene expression in different situations (Ratovitski, 2010). Upon further analysis of the amplified S. apella region, we identified binding sites for many transcription factors (Figure 1), the most relevant being CDXA, USF, C/EBP and AP-1.

The family of $C d x$ homeobox genes is important for early intestinal epithelial cell differentiation and maintenance and is a major transcription factor that induces the intestinal phenotype, resulting in intestinal metaplasia when expressed in an uncontrolled manner (Barros et al., 2010). In humans, $C d x$ expression is induced in the presence of $H$. pylori and is considered important in gastric carcinogenesis, especially in the intestinal type (Gutiérrez-González and Wright, 2008).

The C/EBP (CCAAT / enhancer binding protein) transcription factor revealed in our analysis has a conserved leucine zipper sequence involved in its homo- and hete- rodimerization and DNA binding. The presence of the $\mathrm{C} / \mathrm{EBP}$ binding site in the $\mathrm{COX}-2$ promoter is well documented, and its binding results in $C O X-2$ overexpression, including in gastric tumors (Regalo et al., 2006).

We can also highlight AP-1, which plays an important role in carcinogenesis promotion (Santos et al., 2011) and USF (Upstream Stimulating Factor), which belongs to the Helix-Loop-Helix-Leucine Zipper protein family (Corre and Galibert, 2005). Both are known participants in COX-2 transcriptional activation (Santos et al., 2011; Cho et al., 2012).

DNA methylation has also been reported to regulate $C O X-2$ gene expression and our MSP results revealed a hypermethylated pattern in the S. apella COX-2 gene promoter. However, a comparison of these results with immunohistochemical analysis did not identify a negative correlation that would confirm the involvement of methylation in $C O X-2$ gene inactivation. Among the various hypotheses for this lack of correlation between the methylation profile and immunohistochemistry, it is possible that the S. apella promoter region analyzed here does not represent a key region for COX-2 expression (Maat et al., 2007), making further studies on $C O X-2$ transcriptional regulation necessary.

Our immunohistochemical analysis demonstrated the expression of COX-2 protein in all pre-neoplastic lesions and tumor samples and the lack of expression in normal gastric tissue samples which is confirmed by the results of Lim et al. (2000) that COX-2 protein is overexpressed in gastric cancer tissues compared to normal gastric mucosa.

Our results suggest a similarity between the $S$. apella and human $C O X-2$ promoter sequence, suggesting that $S$. apella is a good animal model for gastric carcinogenesis. Moreover, the lack of correlation between promoter methylation and immunohistochemistry results suggest that this epigenetic mechanism in the analyzed promoter region is not crucial in S. apella COX-2 regulation.

\section{Acknowledgments}

The authors would like to thank to Centro Nacional de Primatas (CENP) for providing the animals in this study and to Conselho Nacional de Desenvolvimento Científico e Tecnológico (550885/2007-2) for funding. D.P. was awarded with a master fellowship from the Coordenação de Aperfeiçoamento de Pessoal de Nível Superior (CAPES).

\section{References}

Alves MK, Ferrasi AC, Lima VP, Ferreira MV, de Moura MIMC and Rabenhorst SH (2011) Inactivation of COX-2, HMLH1 and CDKN2A gene by promoter methylation in gastric cancer: relationship with histological subtype, tumor location and Helicobacter pylori genotype. Pathobiology 78:266276.

Barros R, Camilo V, Pereira B, Freund J-N, David L and Almeida R (2010) Pathophysiology of intestinal metaplasia of the 
stomach: emphasis on CDX2 regulation. Biochem Soc Trans 38:358-363.

Cheng J and Fan XM (2013) Role of cyclooxygenase-2 in gastric cancer development and progression. World J Gastroenterol 19:7361-7368.

Cho D-I, Kim S-Y, Zheng M, Jin M, Choi HK, Yi AK and Kim KM (2012) Identification of cis-acting elements and signaling components of high affinity IgE receptor that regulate the expression of cyclooxygenase-2. Cell Physiol Biochem 29:725-736.

Corre S and Galibert MD (2005) Upstream stimulating factors: Highly versatile stress-responsive transcription factors. Pigment Cell Res 18:337-348.

Costa JFFB, Leal MF, Silva TCR, Andrade Junior EF, Rezende AP, Muniz JA, Lacreta Junior AC, Assumpção PP, Calcagno DQ, Demachki S, et al. (2011) Experimental gastric carcinogenesis in Cebus apella nonhuman primates. PLoS One 6:e21988.

de Maat MF, van de Velde CJ, Umetani N, de Heer P, Putter H, van Hoesel AQ, Meijer GA, van Grieken NC, Kuppen PJ, Bilchik AJ, et al. (2007) Epigenetic silencing of cyclooxygenase-2 affects clinical outcome in gastric cancer. J Clin Oncol 25:4887-4894.

Echizen K, Hirose O, Maeda Y and Oshima M (2016) Inflammation in gastric cancer: Interplay of the COX-2/prostaglandin E2 and Toll-like receptor/MyD88 pathways. Cancer Sci 107:391-397.

Gaetti-Jardim Jr E, Monti LM, Nicolas Ciesielski FI, GaettiJardim EC, Okamoto AC, Schweitzer CM and Avila-Campos MJ (2012) Subgengival microbiota from Cebus apella (capuchin monkey) with different periodontal conditions. Anaerobe 18:263-269.

Gutiérrez-González L and Wright NA (2008) Biology of intestinal metaplasia in 2008: More than a simple phenotypic alteration. Dig Liver Dis 40:510-522.

Hall T (2011) BioEdit: An important software for molecular biology. GERF Bull Biosci 2:60-61.

Heinemeyer T, Wingender E, Reuter I, Hermjakob H, Kel AE, Kel OV, Ignatieva EV, Ananko EA, Podkolodnaya OA, Kolpakov FA, et al. (1988) Databases on transcriptional regulation: TRANSFAC, TRRD, and COMPEL. Nucleic Acids Res 26:364-370.

Herman JG, Graff JR, Myöhänen S, Nelkin B D and Baylin SB (1996) Methylation-specific PCR: A novel PCR assay for methylation status of CpG islands. Proc Natl Acad Sci U S A 93:9821-9826.

Hsu SM, Raine L and Fanger H (1981) Use of avidin-biotinperoxidase complex $(\mathrm{ABC})$ in immunoperoxidase techniques: A comparison between $\mathrm{ABC}$ and unlabeled antibody (PAP) procedures. J Histochem Cytochem 29:577-580.

Kinoshita H, Hirata Y, Nakagawa H, Sakamoto K, Hayakawa Y, Takahashi R, Nakata W, Sakitani K, Serizawa T, Hikiba Y, et al. (2013) Interleukin-6 mediates epithelial-stromal interactions and promotes gastric tumorigenesis. PLoS One 8:e60914.

Lauren P (1965) The two histological main types of gastric carcinoma: diffuse and so-called intestinal type carcinoma. Acta Pathol Microbiol Scand 64:31-49.

Li LC and Dahiya R (2002) MethPrimer: Designing primers for methylation PCRs. Bioinformatics 18:1427-1431.
Li Y, Dai L, Zhang J, Wang P, Chai Y, Ye H, Zhang J and Wang K (2012) Cyclooxygenase-2 polymorphisms and the risk of gastric cancer in various degrees of relationship in the Chinese Han population. Oncol Lett 3:107-112.

Lim HY, Joo HJ, Choi JH, Yi JW, Yang MS, Cho DY, Kim HS, Nam DK, Lee KB and Kim HC (2000) Increased expression of cyclooxygenase-2 protein in human gastric carcinoma. Clin Cancer Res 6:519-525.

Maat MFG, van de Velde CJH, Umetani N, de Heer P, Putter H, van Hoesel AQ, Meijer GA, van Grieken NC, Kuppen PJ, Bilchik AJ, et al. (2007) Epigenetic silencing of Cyclooxygenase-2 affects clinical outcome in gastric cancer. J Clin Oncol 25:4887-4894.

Oshima H and Oshima R (2013) The role of PGE2-associated inflammatory responses in gastric cancer development. Semin Immunopathol 35:139-150.

Puente XS, Velasco G, Gutiérrez-Fernández A, Bertranpetit J, King MC and López-Otín C (2006) Comparative analysis of cancer genes in the human and chimpanzee genomes. BMC Genomics 7:15.

Ratovitski EA (2010). LKB1/PEA3/ANp63 pathway regulates PTGS-2 (COX-2) transcription in lung cancer cells upon cigarette smoke exposure. Oxid Med Cell Longev 3:317324.

Regalo G, Canedo P, Suriano G, Resende C, Campos ML, Oliveira MJ, Figueiredo C, Rodrigues-Pereira P, Blin N, Seruca $\mathrm{R}$, et al. (2006) C/EBPbeta is over-expressed in gastric carcinogenesis and is associated with COX-2 expression. J Pathol 210:398-404.

Rivas-Ortiz CI, Lopez-Vidal Y, Arredondo-Hernandez LJR and Castillo-Rojas G (2017) Genetic alterations in gastric cancer associated with Helicobacter pylori infection. Front Med $4: 47$.

Santos RCV, Rico MAP, Bartrons R, Pujol FV, Rosa JL and de Oliveira JR (2011) The transcriptional activation of the cyclooxygenase- 2 gene in zymosan-activated macrophages is dependent on NF-kappa B, C/EBP, AP-1, and CRE sites. Inflammation 34:653-658.

Takayama S, Thorgeirsson UP and Adamson RH (2008) Chemical carcinogenesis studies in nonhuman primates. Proc Jpn Acad Ser B Phys Biol Sci 84:176-188.

Thiel A, Mrena J and Ristimäki A (2011) Cyclooxygenase-2 and gastric cancer. Cancer Metastasis Rev 30:387-395.

Tsukamoto T, Mizoshita T and Tatematsu M (2007) Animal models of stomach carcinogenesis. Toxicol Pathol 35:636-648.

Wang BC, Guo CQ, Sun C, Sun QL, Liu GY and Li DG (2005) Mechanism and clinical significance of cyclooxygenase-2 expression in gastric cancer. World $\mathrm{J}$ Gastroenterol 11:3240-3244.

Wang MT, Honn KV and Nie D (2007) Cyclooxygenases, prostanoids, and tumor progression. Cancer Metastasis Rev 26:525-534.

Yan WF, Sun PC, Nie CF and Wu G (2013) Cyclooxygenase-2 polymorphisms were associated with the risk of gastric cancer: evidence from a meta-analysis based on case-control studies. Tumor Biol 34:3323-3330.

Associate Editor: Emmanuel Dias Neto

License information: This is an open-access article distributed under the terms of the Creative Commons Attribution License (type CC-BY), which permits unrestricted use, distribution and reproduction in any medium, provided the original article is properly cited. 